\title{
Scrum+: A scaled Scrum for the agile global software development project management with multiple models
}

Scrum+: Un Scrum escalado para la gestión de proyectos ágil de desarrollo de software global con múltiples modelos

\author{
César Jesús Pardo-Calvache (D) ${ }^{1 *}$, Piedad Rocío Chilito-Gómez (D) ${ }^{1}$, Daniel Esteban Viveros-Meneses (iD) ${ }^{1}$, Francisco J. \\ Pino (iD) 2 \\ ${ }^{1}$ Grupo de Investigación GTI, Programa de Ingeniería de Sistemas, Facultad de Ingeniería Electrónica y Telecomunicaciones, Universidad \\ del Cauca. Calle 5 \# 4, 70. C. P. 19002. Popayán, Colombia. \\ ${ }^{2}$ Grupo de Investigación IDIS, Programa de Ingeniería de Sistemas, Facultad de Ingeniería Electrónica y Telecomunicaciones, Universidad \\ del Cauca. Calle 5 \# 4, 70. C. P. 19002. Popayán, Colombia.
}

\section{CITE THIS ARTICLE AS: \\ C. J. Pardo, P. R. Chilito, D. E. Viveros and F. J. Pino. "Scrum+: A scaled Scrum for the agile global software development project management with multiple models", Revista Facultad de Ingeniería Universidad de Antioquia, no. 93, pp. 105-116, Oct-Dec 2019 [Online]. Available: https://www.doi.org/ 10.17533//udea.redin. 20190519}

\section{ARTICLE INFO:}

Received: October 05, 2018 Accepted: May 22, 2019 Available online: May 22, 2019

\section{KEYWORDS:}

Development projects, project management, globalization, development models, systems engineering

Proyecto de desarrollo, dirección de proyecto, globalización, modelo de desarrollo, ingeniería de sistemas
ABSTRACT: Nowadays, carrying out a project management is difficult in any situation, even more in global projects of software development, whose environment faces different aspects that make this type of projects even more difficult to manage, for example: lack of coordination, lack of face to face communication, temporary differences, cultural diversity and application of different standards, models and approaches. With the aim of supporting agile global software development (AGSD) project management when multiple models are present, we have defined Scrum+, which is a guide based on Scrum and defines a set of activities, tasks, roles and criteria to support AGSD projects in multimodel environments. We carried out the harmonization of agile approach Scrum along with project management practices defined in multiple models such as: ISO/IEC 15504, ISO 9001 and CMMI-DEV. Likewise, the evaluation of the proposal has been conducted through: (i) its application in a focus group with experts in different related areas and (ii) its assessment of the degree of agility by means 4-DAT method. Based on the analysis of the results and the comments obtained in the focus group, Scrum+ seems to be clear, adequate, and agile. The guide proposed here can serve as reference for studying further aspects related to agile software scaled projects.

RESUMEN: Actualmente, llevar a cabo la gestión de proyectos es difícil en cualquier situación, incluso más en proyectos globales de desarrollo de software, cuyo entorno enfrenta diferentes aspectos que dificultan aún más la gestión de este tipo de proyectos, por ejemplo: falta de coordinación, falta de comunicación cara a cara, diferencias temporales, diversidad cultural y aplicación de diferentes estándares, modelos y enfoques. Con el objetivo de apoyar la gestión de proyectos de desarrollo global de software ágil (DGSA) cuando varios modelos están presentes, hemos definido Scrum+, el cual es una guía basada en Scrum y define un conjunto de actividades, tareas, funciones y criterios para apoyar proyectos DGSA en entornos de multiples modelos. Llevamos a cabo la armonización del enfoque ágil Scrum junto con las prácticas de gestión de proyectos definidas en múltiples modelos, tales como: ISO/IEC 15504, ISO 9001 y CMMI-DEV. Asimismo, la evaluación de la propuesta se realizó a través de: (i) su aplicación en un grupo focal con expertos en diferentes áreas relacionadas y (ii) su evaluación del grado de agilidad mediante el método 4-DAT. Basado en el análisis de los resultados y los comentarios obtenidos en el focus group, se puede considerar que Scrum+ es claro, adecuado y ágil. La guía propuesta aquí puede servir como referencia para estudiar otros aspectos relacionados con proyectos escalados de software ágil.

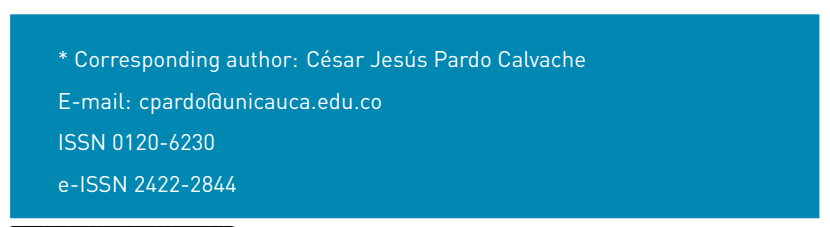

\section{Introduction}

Agile approaches such as the Dynamic Systems Development Method, the family of Agile Crystal 
methods, eXtreme Programming (XP), Adaptive Software Development and Scrum (hereinafter agile approaches), are a set of processes and techniques used for software development, which appear in response to traditional methodologies, such as RUP (Rational Unified Process), characterized by excessive documentation that hinders the development process. However, agile approaches have been originally conceived to be implemented in set teams, generating some concerns about the loss of advantages of these approaches, when used in the Global Software Development (GSD). Due to this, in the last years, a series of solutions have arisen that start from the proposed agile approaches, (especially Scrum) that try to lessen the GSD's own challenges such as communication, coordination and cooperation problems.

Among the main techniques found in the literature we have: Scrum of Scrums [1], Scrumconix [2], LeSS [3], Nexus [4] and SAFe [5], which offer mitigation strategies for the challenges of the GSD [6], since the activities of these agile approaches allow fulfilling the emerging needs in the organizations that apply this type of development.

However, the solutions created do not consider the problems generated in the management of GSD projects when multiple models, standards and approaches (hereinafter reference models) are used to support the management of a GSD project. Additionally, it must be taken into account that the reference models in a GSD context have not been widely developed, and therefore, the efforts to improve processes specifically in a global approach, have had limited success [7].

On the other hand, in the literature it is possible to identify some proposals and solutions that allow supporting the harmonization between the structural and terminological differences using multiple reference models, also known as definition of hybrid models. From these proposals, it was observed that their main effort focuses on obtaining an integrated model that adopts characteristics of different/multiple methodologies, this, from the homogenization of their differences, comparison and integration of best practices, to be later implemented and institutionalized in an organization through a single Software Process Improvement (SPI) [8]. However, until now in none of the found studies, there is evidence of the efforts made about its application in the definition of hybrid models, that allow supporting global software development environments.

Given the situation outlined above, this article presents an agile guide that ease the implementation of practices related to project management in global software development environments, when multiple reference models are present. The defined guide describes different activities, roles and criteria, which should be considered in a GSD project. The Scrum+ guide has been designed to lessen some of the challenges present in the GSD, by adapting proposed solutions and the Scrum harmonization, with other certifiable reference models such as CMMI-DEV, ISO 9001 and ISO/IEC 15504, to provide support to multi-model environments that a global software development project may face. This guide is part of the research efforts that have been conducted in the research groups involved and which aim at defining better agile practices that allow addressing the challenges and needs of current software development companies. This paper is an extension of the conference paper presented in [9], unlike the paper presented previously, here we present in detail the harmonization of multiple models carried out and the correspondence among Scrum and ISO/IEC 15504, ISO 9001 and CMMI-DEV to design the proposal. Likewise, some examples of some flow diagrams are presented.

Apart from this introduction, the article is organized as follows: Section 2 presents a summary of the related works. Section 3 presents the Scrum+ guide, and it describes the activities, tasks and roles proposed. Section 4 presents a summary of the evaluation of the guide carried out through the application of a focus group and an agility assessment. Finally, Section 5 presents the discussion, lessons learned, conclusions and future work.

\section{State of the art}

Based on the results obtained from the literature review made and related to the management of global software development projects in multi-model environments, Table 1 shows some of the developed proposals, that allow the management of global software development projects or projects where multiple development teams are involved.

Considering the related works, it is possible to observe that although there are different proposals that try to lessen some of the challenges of the GSD, there are no studies or proposals that consider the possible multi-model scenarios that can be generated in this type of environments.

\section{Research method}

In order to develop this guide, it was used the Action Research method with multiple linear cycles and a focus group as a research method $[10,11]$. Taking into account the phases and activities proposed by the Action Research methodology, three research cycles were carried out for the development of this proposal. The cycles and activities carried out sequentially and incrementally for the development of the guide are listed below. 
Table 1 Proposals and found solutions. Own source

\begin{tabular}{|c|c|c|c|}
\hline Ref. & Name & Reference Model & Characteristics \\
\hline [1] & Scrum of Scrums & Scrum & $\begin{array}{l}\text { - It is used to scale the traditional Scrum methodology and } \\
\text { to adjust it to larger and more complex projects. } \\
\text { - It has a team divided into sub-teams that act normally, but } \\
\text { each team selects a person to represent it (ambassador). } \\
\text { - It scales the traditional roles of Scrum, to be able to } \\
\text { manage multiple teams through their representatives. }\end{array}$ \\
\hline [2] & Scrumconix & Scrum Iconix & $\begin{array}{l}\text { - It consists of a series of phases known as: Sprint Zero } \\
\text { and Sprint one to N. In the Sprint Zero Scrum teams are } \\
\text { devoted to getting to know the whole project also the } \\
\text { Backlog of the product is proposed using some ICONIX } \\
\text { artifacts. In the sprint one to N the coding and testing } \\
\text { tasks of each deliverable are performed and the next } \\
\text { Sprint is prepared. }\end{array}$ \\
\hline
\end{tabular}

- It defines two frameworks: Less, which is designed to manage up to 8 teams of 8 people each, and LeSS Huge, defined to manage projects with a greater number of members.

[3] LeSS Scrum

- It defines a single Product Backlog and a single definition of Done for all teams, which are managed by a single Product Owner.

- It defines two parts for planning the Sprint, one at the project level and the other at the team level.

- It proposes a general retrospective of maximum 45 minutes each week.

- It interconnects the work of approximately 3 to 9 Scrum teams, under a single Product List.

[4] Nexus Scrum

- It defines a new artifact, the Nexus Sprint backlog, which helps with the transparency during the development of the teams' individual Sprint.

- It contains the levels of the teams, programs and portfolio

- At a team level, it adopts Scrum with XP engineering practices.

[5] SAFe Scrum XP Lean

- At a program level, it defines the concept of an Agile Release Train, which is analogous to the sprint of the team level.

- At a portfolio level the planning is done as epics that define large development initiatives.

- Cycle 1. Conceptual analysis. Here the systematic review of the current state of the art was carried out, related to the agile project software management in distributed environments, in scenarios where multiple models intervene for its management. Also, during the development of this cycle, the different proposals, existing solutions and the sensitive elements to be considered for the definition of the solution were identified and studied.

- Cycle 2. Defining and designing the agile guide. In this stage, the process of harmonization of the different models and standards for project management and the agile Scrum approach was defined. As an outcome of this cycle, the Agile Scrum+ guide is established based on the results obtained from the harmonization process.

- Cycle 3. Evaluation of the proposal. The evaluation of the proposal was carried out through the use of the focus group research method, in which experts participated in different areas related to the proposal. 


\section{Harmonization of multiple models for the definition of the Scrum+}

For the definition of Scrum+, it was out carried the harmonization of multiple models from the comparison and identification of the differences and similarities among the activities defined by the reference models: ISO/IEC 15504 [12], ISO 9001 [13] and CMMI-DEV [14], these reference models were compared 1 to 1 with the agile Scrum approach [15]. The comparison allowed knowing the degree of correspondence between the multiple models. The results of this process were considered to define the activities that allow Scrum+ to support the management of projects in multimodel environments. HFramework was used to carry out this process [8], which is a framework that allows supporting the harmonization of multiple models through a harmonization strategy consisting of three methods: homogenization, comparison and integration. Due to the limited space, this paper presents the results of the harmonization in a summarized way.

Table 2 shows an excerpt example of the comparison template used and the relationships with the specific goal (SG) 1: "Use the project defined process from the process area integrated project management (IPM)" of the CMMI-DEV model and the activities defined by Scrum.

\subsection{Correspondence among Scrum and ISO/IEC 15504, ISO 9001 and CMMI-DEV}

As can be seen in Table 3, regarding the ISO/IEC 15504 standard, $57.1 \%$ (4) of the clauses have a HIGH level of correspondence in relation to the activities proposed by Scrum, while the remaining percentage $42.9 \%$ (3) of the clauses have levels of correspondence among MODERATE, LIGHT and NULL with $14.3 \%$, corresponding to the clauses 3.3.1.4 Process of risk management, 3.3.1.6 Process of measurement and 3.2.1.5 Process of configuration management, respectively. The same occurs with the ISO 9001 standard, 4 of the compared clauses have a $\mathrm{HIGH}$ level of correspondence, the remaining percentage corresponds to the clauses 8.5 Production and supply of the service, 8.1 Operational planning and control and 8.4 Processes control, products and services provided externally. Regarding the CMMI-DEV, it can be seen that $42.9 \%$ (3) of the processing areas have a HIGH level of correspondence, while $28.6 \%$ (2) have a MODERATE level of correspondence with the agile Scrum approach. While the $14.3 \%$ represented by the process Quantitative Project Management area (QPM) retains a LIGHT level of correspondence, similarly $14.3 \%$ (1) of the CMMI-DEV process areas have no correspondence or relationship among the activities defined by Scrum. The process area that has a NULL correspondence with Scrum is the
Supplier Agreement Management (SAM) area.

With the comparison of the models, it was possible to identify that out of 21 relationships that can exist between the clauses and process areas of the reference models and Scrum, 3 of them were classified with a NULL level of correspondence, that is $14.3 \%$ of the related processes elements have no correspondence, while $85.7 \%$ (18) are related in some degree to Scrum activities.

\section{Scrum+: guide for the management of projects in organizations with global environments when multiple reference models are present}

The purpose of Scrum + is to guide organizations in project management in global environments when multiple reference models are present. This guide adapts Scrum and some of the methodologies that scale it like Nexus, LeSS and Scrum of Scrums; used in global development projects. Scrum+ defines its roles, activities and artifacts according to Scrum as an agile approach to project management. So, its components will be familiar to those who have knowledge in Scrum.

As a result of the harmonization process, a Scrum list of activities, which cover different areas of the aforementioned reference models was obtained. These activities were considered to define Scrum+.

\subsection{Roles}

Scrum + scales some of the traditional Scrum roles and also defines new roles that facilitate the interaction between distributed teams and their members, see Table 4.

\subsection{Scrum+ activities}

Scrum+ is composed of seventeen (17) main activities, which are distributed in ten (10) phases described below:

\section{Phase 1. Initiation}

During this phase, the initial activities of a global software development project are carried out. In this phase, the vision of the project is created; the requirement for the distributed development is defined, where the distribution needs, according to the general vision of the project are detailed. The distributed development centers that fulfill the distribution needs through standards, geographic 
Table 2 Excerpt example of the comparison template used between the specific goal (SG) 1 of CMMI and the Scrum practices. Own

\begin{abstract}
Mapping direction: From the Scrum Model to Model CMMI-DEV.
\end{abstract}

Mapped process elements: Activities and specific practices

Mapping question: What activities defined by Scrum support the specific practices of the CMMI-DEV model?

Mapping Objective: To determine which Scrum activities correspond to the specific practices of the Integrated

Project Management (IPM) process area of the specific goal. Use the process defined project in the CMMI-DEV Model.

\begin{tabular}{|c|c|c|c|c|c|c|}
\hline \multicolumn{7}{|c|}{ Model CMMI-DEV } \\
\hline \multicolumn{7}{|c|}{ SG 1 Use the defined project process } \\
\hline 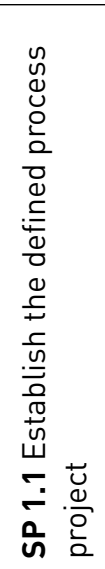 & 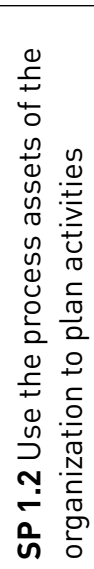 & 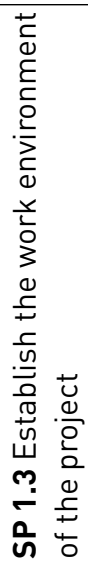 & 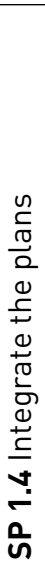 & 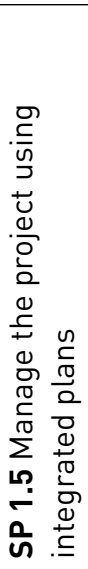 & 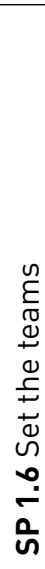 & 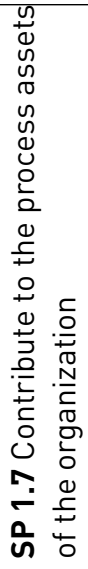 \\
\hline $\mathbf{X}$ & $X$ & & & & & \\
\hline $\mathbf{X}$ & $\mathbf{X}$ & & & & $\mathbf{X}$ & \\
\hline & $\mathbf{X}$ & & & & & \\
\hline & & & & & & \\
\hline
\end{tabular}

Table 3 Correspondence among Scrum and ISO/IEC 15504, ISO 9001 and CMMI-DEV. Own source

\begin{tabular}{|c|c|c|c|c|c|c|}
\hline \multicolumn{7}{|c|}{ Clauses ISO/IEC 15504} \\
\hline 3.2.1.1 & 3.2.1.3 & 3.2 .1 .4 & 3.2 .1 .5 & 3.2 .1 .6 & 3.3.1.3 & 3.3.1.4 \\
\hline $83.33 \%(H)$ & $83.33 \%(H)$ & $75 \%(H)$ & $0 \%(N)$ & $28.57 \%$ (L) & $75 \%(H)$ & $66.67 \%(M)$ \\
\hline \multicolumn{7}{|c|}{ Clauses ISO 9001} \\
\hline 8.1 & 8.2 & 8.3 & 8.4 & 8.5 & 8.6 & 8.7 \\
\hline $42.85 \%(L)$ & $100 \%(H)$ & $83.33 \%(A)$ & $0 \%(N)$ & $66.67 \%(\mathrm{M})$ & $100 \%(H)$ & $100 \%(H)$ \\
\hline \multicolumn{7}{|c|}{ Process areas in CMMI-DEV } \\
\hline IPM & PCM & PP & QPM & REQM & RSKM & SAM \\
\hline $90 \%(H)$ & $80 \%(M)$ & $50 \%(M)$ & $14.28 \%(\mathrm{~L})$ & $100 \%(H)$ & $57.14 \%(M)$ & $0 \%(N)$ \\
\hline
\end{tabular}

Acronyms used:

- Integrated Project Management (IPM), Project Monitoring and Control (PMC), Project Planning (PP), Quantitative Project Management (QPM), Requirements Management (REQM), Risk Management (RSKM), Supplier Agreement Management (SAM)

- High (H), Moderate(M), Light (L), Null (N)

location, developers' work capacity, services offered are decided, the Scrum+ team is conformed.

\section{Phase 2. SprintZero+}

This phase is done with the help of the Scrum+ team and the technical representatives who plan and define strategies that facilitate their coordination during the development of the project. In addition, the selection of the technical representative of each team to participate during the SprintZero+ meeting is made. The SprintZero+ meeting aims to coordinate the activities that the teams will develop during the project. Once the SprintZero+ meeting is over, the technical representatives return to their teams and socialize the decisions made.

\section{Phase 3. Product backlog refinement}

During this phase, the Product Backlog is reviewed to add, eliminate or re-estimate previously defined user stories. It is necessary that during this phase, the user stories are divided minimizing or eliminating any type of 
Table 4 Roles in Scrum+

\begin{tabular}{ll}
\hline Name & Despcription \\
\hline Scrum+ Team & $\begin{array}{l}\text { In charge of coordinating, supervising and supporting the distributed teams that are } \\
\text { part of the project. }\end{array}$ \\
\hline $\begin{array}{l}\text { Technical } \\
\text { Representative }\end{array}$ & $\begin{array}{l}\text { It represents the teams in the different meetings held throughout the project. This } \\
\text { representative can be alternated, depending on the topic to be discussed in each } \\
\text { event. }\end{array}$ \\
\hline Scrum Master+ & $\begin{array}{l}\text { It is in charge of guiding the coordination and collaboration between the Technical } \\
\text { Representatives and the Product Owner+ (P0+). }\end{array}$ \\
\hline $\begin{array}{l}\text { Product Owner+ } \\
\text { (P0+) }\end{array}$ & Responsible for managing the project product stack. \\
\hline
\end{tabular}

dependence among them. It is suggested to perform a risk assessment in each of the tasks or user stories of the Product Backlog, as from which actions will be taken on the existing dependences.

\section{Phase 4. Planning and assessment}

During this phase, the SprintPlaning + meeting is held, where the PO+ socializes the client's needs, performs the necessary orientations and prioritizes the user stories. During this meeting, the technical representatives based on their experience will determine the tasks that their team can develop during the Sprint. Once this meeting is over, Sprint planning is done within each team.

\section{Phase 5. Implementation and integration}

In this phase, the teams carry out the implementation of the functionalities of their respective Sprint Backlog, and if necessary, a meeting is held among the technical representatives of each team to socialize the current status of each team's work and the obstacles that their work can generate to other teams.

\section{Phase 6. Sprint review}

During this phase the increments are reviewed and it is decided if the ones made by each team are approved. In this phase, the Sprint review meeting is held, where each team presents their increment to their Product Owner. Once this meeting is over, the Sprint+ meeting is held, where the increments delivered by each of the teams are reviewed.

\section{Phase 7. Integration+}

During the development of this phase, the Scrum+ team is responsible for the integration of the increments delivered by the different teams. This integration is left in charge of the Scrum + team to avoid coordination and communication problems when carrying out this task. Likewise, during this phase the Scrum+ team is responsible for integrating and sharing the different management artifacts generated by the different teams, this in order to keep track of the progress of each team and the project in general.

\section{Phase 8. Release}

During the release phase, the technical representatives along with their Scrum Master, deliver the integrated increment to the client and the $\mathrm{PO}+$, who will give a feedback of the work done.

\section{Phase 9. Sprint retrospective}

During this phase, each team performs a self-analysis of their work in the Sprint and identifies their strengths and weaknesses at a team and project level, with the aim of planning improvement actions. Once the Sprint Retrospective meeting is over, the Sprint+ Retrospective is held, where the technical representatives share the results of the retrospective of each team. Based on these results, the Scrum Master+ proposes an improvement plan at a project level.

\section{Phase 10. Change management}

The needs of the interested parties are presented during the change management meeting, and the Product Owners are in charge of socializing these needs to each of their teams. Team members estimate the effort and cost of these changes and the Product Owner informs the interested parties of the associated costs. In case of being accepted by the client, the Product Backlog is re-prioritized considering the new needs presented. In spite of the flexibility and adaptation to the change offered by Scrum+ throughout the development of the project, it is suggested that the change management be carried out at the end of the Sprint to facilitate the coordination and control of the project and its members. In addition, Scrum+ compiles a series of recommendations for the management of the teams, the making of the events and the selection of support tools. Table 5 presents some of the mentioned recommendations. 
Table 5 Scrum+ Strategies. Own source

\begin{tabular}{l}
\hline Strategy for the coordination of meetings [16] \\
\hline Documented meetings: Detailed documentation is made and shared with those who do not attend the meeting. \\
\hline Liaison meetings: Two meetings are held at different times with a member of the team that fulfills the role of \\
"liaison" among the participants of the meetings. \\
\hline Changing schedules: Meetings are held at different times, so that on occasions it benefits some teams and \\
sometimes others. \\
Share the pain: A schedule that benefits all project teams is selected. \\
Feel the pain: Meetings are always held at the same time, so that there will be teams or team members who \\
always "feel the pain". \\
\hline Characteristics of the support tools [17-19] \\
\hline Security: The tool must allow the creation of profiles for each member and must guarantee the assignment of \\
privileges according to their role in the project. \\
\hline Availability: For being a global environment, the tool should be accessible from anywhere at any time of the day. \\
\hline Communication: The tool should favor synchronous communication (video conferences, chats, voice calls) and / \\
or asynchronous communication (forums, wikis or e-mails) between the members of the teams. \\
\hline Awareness Mechanisms: Awareness mechanisms allow team members to be aware of what their colleagues \\
are doing. The most common Awareness mechanisms are: Common work spaces, visualization of connected \\
users, identification of the actions carried out by a user through colors, notifications of available users and map \\
of hierarchies of team members, among others. \\
\hline Knowledge management: The support tools must allow registering and sharing the knowledge generated by the \\
project's members, not only in technical matters, but also allow the management of knowledge about the cultural \\
aspects of the other teams and their members.
\end{tabular}

Some examples of flowcharts defined in Scrum+ can be seen in Figure 1 and Figure 2. Figure 1 shows the flowchart for the activity related to the creation of the Product Backlog. Figure 2 shows the flowchart for the SprintZero+ meeting Scrum+ uses the notation business process modeling notation or BPMN and incorporates a special notation, the rectangles (activity / task) of green color represent distributed activities, a new icon is added in the form of clouds and roles, which represents the artifacts that should be shared among the distributed teams, the blue rectangles (activity / task) maintain the same original meaning of the notation and are used to represent the activities that are not done in a distributed manner. The complete and detailed version of the proposed guide can be found at: http://artemisa.unicauca.edu.co/ piedadchilito/

\section{Proposal evaluation}

This section shows the evaluation process of the proposed Scrum+ guide, through a focus group applied to experts in the quality area, project management, agile approaches, IT governance and people who are part of the local software industry. Additionally, a formal agility evaluation of the proposal was made.

\subsection{Focus group}

In [11], the focus group is referred to as a quick and cost-effective empirical method for obtaining qualitative information and feedback from a specific group. The focus group is adequate to obtain information from the participants about research questions or new concepts. It also allows the initial evaluation of potential solutions based on the opinions of participants or potential users. It also allows compiling recommendations of learned lessons or generating new ideas. The evaluation of the proposal was carried out under the parameters established in [11]. According to [18], the number of members in a focus group can range from 3 to 12 participants, to have sufficient sustainability and carry out the objective evaluation of the proposal, we decided according to our experience, to make an adequate selection of the participants according to their experience in the subject addressed in the research (see section related to design of discussion groups).

\subsection{Focus group objectives}

- To obtain feedback from participants on questions and concepts defined in Scrum+ as a guide that facilitates the management of global software development projects when multiple reference models intervene. 


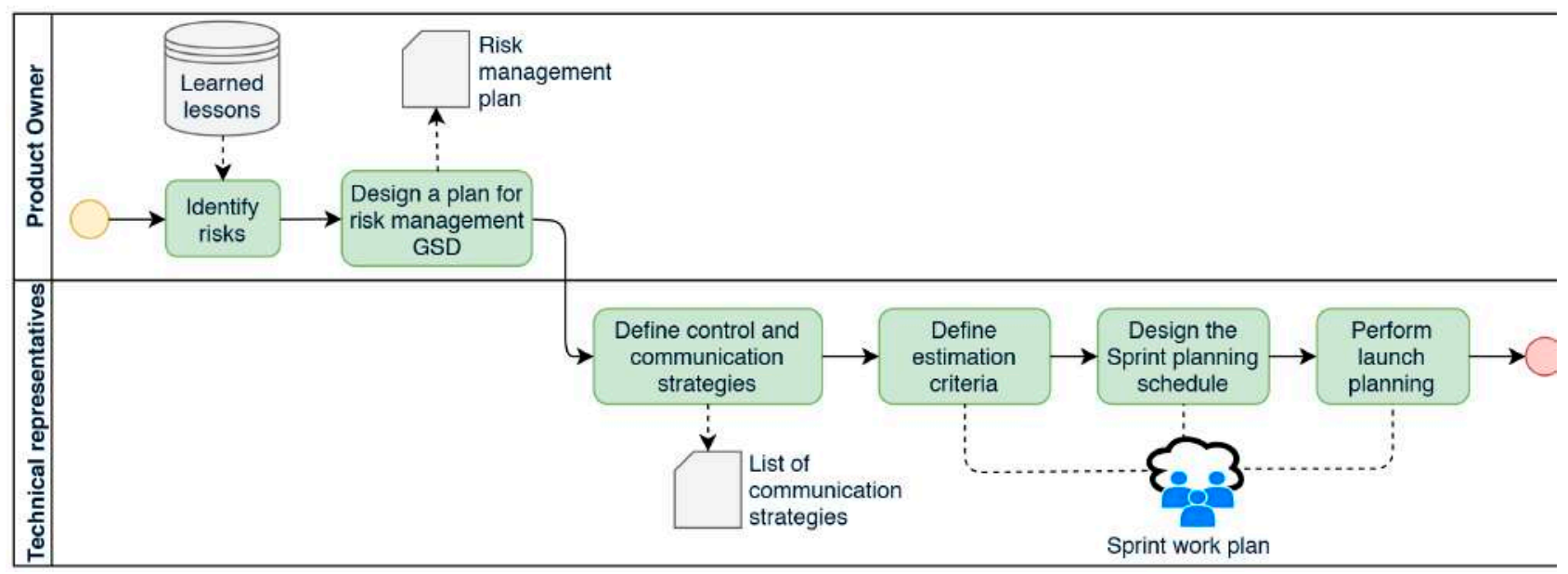

Figure 1 Example of the flow diagram related to the activity: Creation of the Product Backlog in Scrum+. Own source

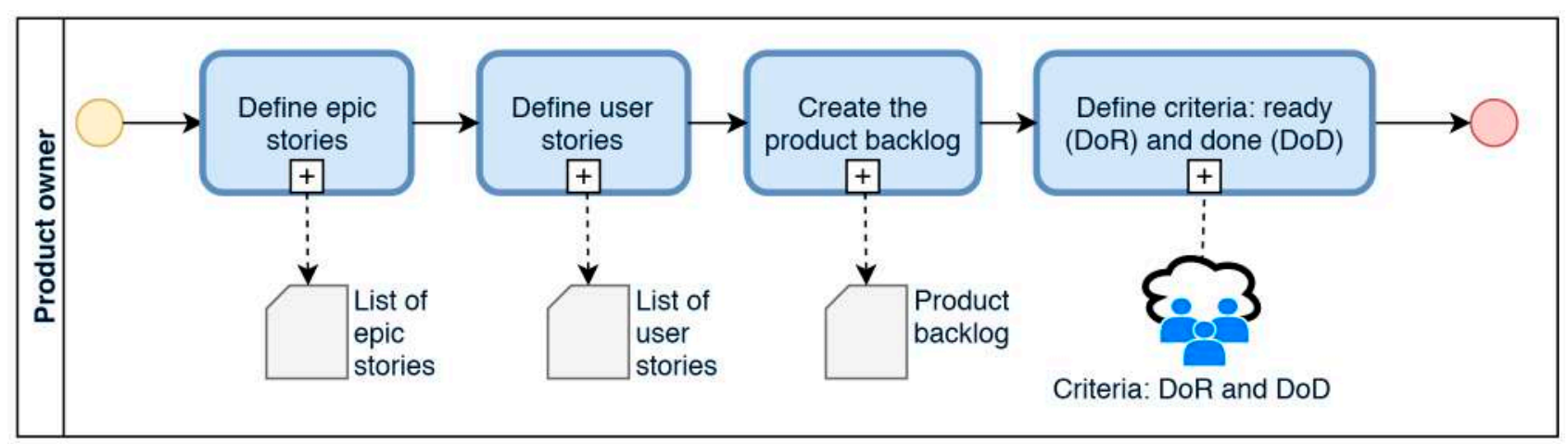

Figure 2 Example of the flow diagram related to the activity: SprintZero+ Meeting in Scrum+. Own source

\subsection{Research objectives}

- To conduct the initial evaluation of Scrum+ as a potential solution based on practitioners and potential users.

- To collect recommendations of learned lessons or generate new ideas.

- To get feedback on how the guide and concepts are presented.

\subsection{Design of discussion groups}

For the selection of the focus group participants, the following criteria have been defined:

- People with theoretical/practical knowledge in Software Development Project Management.

- People with experience in the Software Industry.

- People with theoretical/practical knowledge in global software development projects.

- People with knowledge in the area of IT governance.

\subsection{Analysis of results}

Once the application of the focus group was finished, an analysis of the questionnaires completed by each of the participants (7 in total) and a classification of the contributions made during the discussion sessions was carried out. The following Table 6 presents the questions asked and the response count. The participants of the focus group answered according to the following scale based on their level of compliance: totally in agreement (TA), largely agree (LA), partially agree (PA), little agreement (LTA) and disagree (D).

Figure 3 graphically presents the results previously presented in Table 6. In general, it can be seen that the participants agreed with most of the aspects evaluated during the focus group session. However, in Figure 3, it is also possible to observe that there are some aspects such as those evaluated in the questions: P5, P7 and P8 that are not considered as favorable, therefore, improvement actions were considered. In the following section in Table 7 the improvement actions carried out are summarized. 
Table 6 Results of the questions performed in focus group. Own Source

\begin{tabular}{|c|c|c|c|c|c|c|}
\hline \multirow{2}{*}{ Id. } & \multirow{2}{*}{ Questions } & \multicolumn{5}{|c|}{ Results } \\
\hline & & 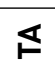 & $\unlhd$ & 【 & $\mathbb{G}$ & 口 \\
\hline P1 & Is the Scrum+ guide easy to understand? & 1 & 4 & 2 & 0 & 0 \\
\hline P2 & $\begin{array}{l}\text { How important do you think it is to use a guide that facilitates the } \\
\text { management of global software Development projects, when multiple } \\
\text { reference models intervene? }\end{array}$ & 6 & 1 & 0 & 0 & 0 \\
\hline P3 & $\begin{array}{l}\text { Do you consider the application of the guide feasible in a GSD project when } \\
\text { multiple reference models intervene? }\end{array}$ & 2 & 3 & 2 & 0 & 0 \\
\hline P4 & $\begin{array}{l}\text { Do you consider that the activities defined in the guide are feasible in a multi- } \\
\text { model GSD project? }\end{array}$ & 0 & 2 & 5 & 0 & 0 \\
\hline P5 & $\begin{array}{l}\text { Do you think the implementation of the Scrum + guide in a GSD project } \\
\text { is simple? }\end{array}$ & 0 & 2 & 4 & 0 & 1 \\
\hline P6 & $\begin{array}{l}\text { Do you think the Scrum+ application is useful to lessen the challenges of a } \\
\text { GSD project? }\end{array}$ & 0 & 5 & 2 & 0 & 0 \\
\hline P7 & $\begin{array}{l}\text { Are the Scrum+ components practical and can they be used in global software } \\
\text { development projects? }\end{array}$ & 0 & 4 & 2 & 0 & 1 \\
\hline P8 & $\begin{array}{l}\text { Do you think that the roles and activities defined in Scrum+ are self- } \\
\text { explanatory and do not need further explanation to be implemented } \\
\text { correctly? }\end{array}$ & 2 & 0 & 3 & 1 & 1 \\
\hline P9 & $\begin{array}{l}\text { Do you consider that the guide is generic enough to adopt practices typical of } \\
\text { other reference models? }\end{array}$ & 1 & 1 & 4 & 1 & 0 \\
\hline
\end{tabular}

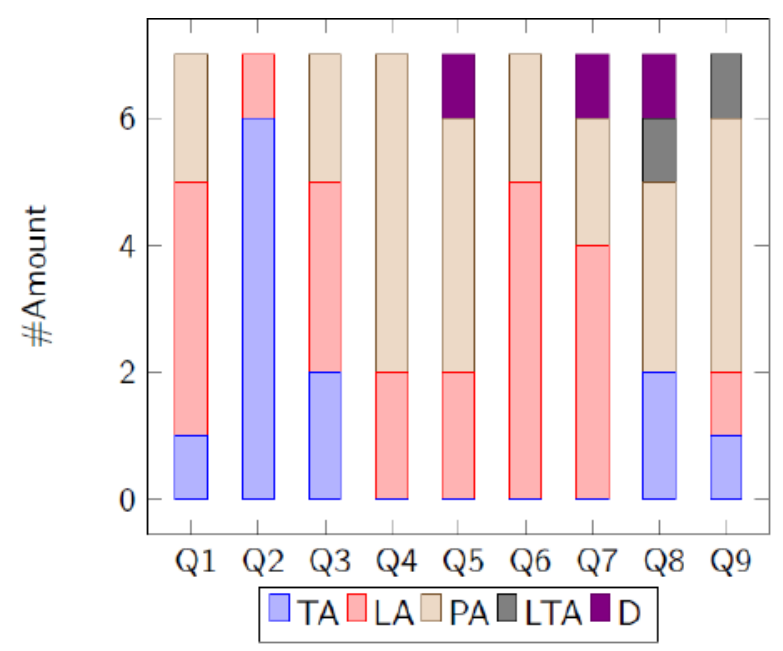

Figure 3 Focus grup consolidated questions. Own source

\section{Improvement actions}

Based on the analysis of the results and the comments obtained in the discussion session, improvement actions were carried out on the guide, thus obtaining a final version, which is presented in this document. The following Table 7 shows the improvement actions carried out on the Scrum+ guide.

\section{Analysis of the degree of agility of Scrum+}

In order to determine if Scrum+ can be considered as an agile guide that supports the management of global software development projects, an additional evaluation was carried out using the analytical framework known as 4-DAT [19], which allows performing a qualitative and quantitative evaluation to determine the degree of agility of any existing or under construction approach, method or process through 4 dimensions: (i) Method Scope, (ii) Agility Characterization, (iii) Agile Value Characterization and (iv) Software Process Characterization. Due to the space limit, just an extract of the application of the 4-DAT framework and the findings obtained for dimension 2 are presented. Table 8 presents a set of characteristics to be evaluated in the dimension 2 proposed in 4-DAT and with which a methodology or proposal must be considered to be agile. The evaluation of the proposal was carried out by analyzing the phases defined in Scrum+, assigning the value of one (1) to the characteristics that are present in them and zero ( 0 ) if the characteristic is not present in the analyzed phase. The results of the evaluation of characteristics in the dimension 2 are presented in Table 9.

As a result of the evaluation, and after applying the 4 dimensions proposed in 4-DAT, and the relationship with the assessment of agility in dimension 2, an $82 \%$ degree of agility was obtained, which allows us to consider that 
Table 7 Scrum+ improvement actions

\begin{tabular}{ll}
\hline \# & Improvement action \\
\hline $\mathbf{1}$ & $\begin{array}{l}\text { The implementation and integration activity was modified, updating the way the Scrum+ meeting should be } \\
\text { carried out. A conditional is added, where the need for the Scrum+ meeting is verified, giving the teams } \\
\text { freedom to carry it out. }\end{array}$ \\
& $\begin{array}{l}\text { The way Scrum+ manages the risks is updated. Three tasks are added for risk management: One called "Make } \\
\text { plan for DSD risk management", which must be carried out during the SprintZero+ activity. The second task } \\
\text { is added in the maintenance phase of the Product Backlog. This task is called "Assessment of the risk in the } \\
\text { dependencies", which must be carried out in the Refining Activity of the Product Backlog Phase 3. The third } \\
\text { task is added in the Sprint+ revision activity. }\end{array}$ \\
\hline $\mathbf{3}$ & $\begin{array}{l}\text { The responsibility of "Right of decision" is added to the technical representatives, in order to provide better } \\
\text { coordination and control among the teams and their members. }\end{array}$ \\
\hline $\mathbf{4}$ & $\begin{array}{l}\text { In order to improve the understanding of the support provided by Scrum+ to multi-model environments, a } \\
\text { table of equivalences is created among the activities of the ISO 9001, ISO 15504 and CMMI-DEV models with } \\
\text { the Scrum+ activities. }\end{array}$ \\
\hline $\mathbf{5}$ & The description of the artifact is updated: "List of not completed tasks" in order to improve its understanding. \\
\hline $\mathbf{6}$ & $\begin{array}{l}\text { The writing and general presentation of the guide is updated in order to improve its understanding and to } \\
\text { eliminate some typographical or design errors. }\end{array}$ \\
\hline
\end{tabular}

Table 8 Example of characteristics to be evaluated in the dimension 2 proposed in 4-DAT

\begin{tabular}{llll}
\hline \# & Variable & Characteristic & Description \\
\hline $\mathbf{1}$ & FY & Flexibility. & Does the method adapt to expected or unexpected changes? \\
\hline $\mathbf{2}$ & SD & Speed. & Does the method produce fast results? \\
\hline $\mathbf{3}$ & LS & Lightness. & $\begin{array}{l}\text { Does the method reduce times, use economic, simple and } \\
\text { quality instruments for production? }\end{array}$ \\
\hline $\mathbf{4}$ & LG & $\begin{array}{l}\text { Continuous } \\
\text { improvement. }\end{array}$ & $\begin{array}{l}\text { Does the method make use of updated knowledge and } \\
\text { previous experiences to favor a learning environment? }\end{array}$ \\
\hline $\mathbf{5}$ & RS & Adaptability. & Does the method show a level of adaptation? \\
\hline
\end{tabular}

Table 9 Results of the evaluation of characteristics in the dimension 2 proposed in 4-DAT

\begin{tabular}{|c|c|c|c|c|c|c|c|}
\hline \multicolumn{8}{|c|}{ Degree of agility in Scrum+ } \\
\hline \multirow{2}{*}{ \# } & \multirow{2}{*}{ Phases } & \multicolumn{6}{|c|}{ Agility criteria. } \\
\hline & & FY & SD & LS & LG & RS & Total \\
\hline 1 & Initiation & 0 & 1 & 1 & 1 & 1 & 4 \\
\hline 2 & SprintZero & 0 & 1 & 0 & 1 & 1 & 3 \\
\hline 3 & Refinement of the Product Backlog & 1 & 1 & 1 & 1 & 1 & 5 \\
\hline 4 & Planning and estimation & 0 & 1 & 1 & 1 & 1 & 4 \\
\hline 5 & Implementation & 1 & 1 & 1 & 1 & 1 & 5 \\
\hline 6 & Sprint Review & 1 & 1 & 1 & 1 & 1 & 5 \\
\hline 7 & Integration & 0 & 1 & 1 & 0 & 0 & 2 \\
\hline 8 & Release & 1 & 1 & 1 & 0 & 1 & 4 \\
\hline 9 & Sprint Retrospective & 0 & 1 & 1 & 1 & 1 & 4 \\
\hline 10 & Change management & 1 & 1 & 1 & 1 & 1 & 5 \\
\hline 11 & Total & 5 & 10 & 9 & 8 & 9 & 41 \\
\hline 12 & Degree of agility & $5 / 10$ & $10 / 10$ & $9 / 10$ & $8 / 10$ & $9 / 10$ & $41 / 50$ \\
\hline 13 & Degree of agility\% & $50 \%$ & $100 \%$ & $90 \%$ & $80 \%$ & $90 \%$ & $82 \%$ \\
\hline
\end{tabular}

the proposal has a favorable degree of agility for the management of global software development projects.

Because the final objective of evaluating the degree of agility of the proposal, is to determine if it can be considered as an agile guide for the management of
DSD projects, it is important to highlight that there was a certain degree of subjectivity during the evaluation of agility through the 4-DAT framework, to reduce bias during the evaluation of the proposal, an effort has been made to reduce the degree of subjectivity through the application of two evaluations through focus groups, in which the 
participants were asked about some aspects of agility present in the proposal.

\section{Conclusions}

From the development of this work, it is possible to conclude that the global agile development has become a trend in recent years, making more and more proposals for this type of projects to appear. However, these proposals leave many open gaps and do not fully cover the needs of global software development projects, this is because the vast majority of proposals are designed for specific cases. For this reason, a new approach that meets the needs of any type of organization is necessary.

Although several proposals that scale agile aproaches have been designed, many of them do not consider that the development of a project can be carried out by different service providers, which can work with different models of reference for the development of your projects.

As future work, a new evaluation of this proposal is expected through one or more case studies to verify compliance with the objectives of the guide under a real environment. Similarly, it is expected to develop a web tool that allows managing global software development projects through Scrum+. On the other hand, some future works will be addressed, they are: (i) to develop a software tool that supports the proposal. So far, the guide is a theoretical support for the management of GSD projects under multi-model environments, in the future it is expected to develop a software tool based on the definition of the Scrum + guide that complements the GSD project management process in environments multi-model. (ii) To define metrics for the management of GSD projects. According to the results obtained in the systematic review carried out, it was possible to determine that measurements and metrics are important elements for the successful development of GSD project management. Currently, the research group is working on the definition of metrics for the management of distributed software development projects, it is expected that the results of this research work can be adapted to the Scrum+ guide and thus complement the control of GSD projects under a multimode environment. (iii) To extend the definition of the proposal with other reference models. So far, the guide has been developed to support the project management practices of the ISO/IEC 15504, ISO 9001 and CMMMI-DEV reference models. However, it is expected that the guide does not limit itself to offer support to the management of projects in organizations that use one of these three models of reference, on the contrary, it is intended to update the guide, which allows the inclusion of other reference models highly used in the industry. (iv) Finally, we hope to use the lessons learned and the knowledge generated to determine which practices should be sensitive to be taken into account as a reference for an effective and successful adoption of practices related to global software development. With results obtained, it is expected to develop a solution that allows evaluating the degree of satisfaction of elements and/or fundamental practices in this type of contexts, this would allow the software companies to identify their strengths and weaknesses, and so, to be able to plan more objective way your process improvement projects.

\section{Acknowledgements}

Professors César Pardo and Francisco Pino thank the University of Cauca, where they currently work as Associate and head Professors respectively.

\section{References}

[1] A. Almutairi and M. R. Qureshi, "The proposal of scaling the roles in scrum of scrums for distributed large projects," Journal of Information Technology and Computer Science (IJITCS), vol. 7, no. 8, pp. 68-74, 2015.

[2] L. T. Portela and G. Borrego, "Scrumconix: Agile and documented method to agsd," in IEEE $11^{\text {th }}$ International Conference on Global Software Engineering (ICGSE), Irvine, CA, USA, 2016, pp. 195-196.

[3] LeSS Framework. LeSS. Accessed Sep. 22, 2018. [Online]. Available: https://goo.gl/9UuAGx

[4] The nexus guide. scrum. Accessed Apr. 25, 2018. [Online]. Available: https://bit.ly/2z9 JmHU

[5] M. Paasivaara, "Adopting SAFe to scale agile in a globally distributed organization," in $12^{\text {th }}$ International Conference on Global Software Engineering (ICGSE), Buenos Aires, Argentina, 2017, pp. 36-40.

[6] R. Sriram and S. K. Mathew, "Global software development using agile methodologies: A review of literature," in International Conference on Management of Innovation \& Technology (ICMIT), Sanur Bali, Indonesia, 2012, pp. 389-393.

[7] M. Niazi, M. A. Babar, and J. M. Verner, "Software process improvement barriers: A cross-cultural comparison," Information and Software Technology, vol. 52, no. 11, pp. 1204-1216, Nov. 2010.

[8] C. Pardo, F. J. Pino, F. García, M. T. Baldassarre, and M. Piattini, "From chaos to the systematic harmonization of multiple reference models: A harmonization framework applied in two case studies," J. Syst. Softw., vol. 86, no. 1, pp. 125-143, Jan. 2013.

[9] P. R. Chilito, D. Viveros, C. J. Pardo, and F. J. Pino, “Scrum+: An agile guide for the global software development (GSD) multi-model project managemen," in IEEE Colombian Conference On Comunications and Computing (COLCOM), Medellín, Colombia, 2008, pp. 1-6.

[10] N. Kock, Information Systems Action Research An Applied View Of Emerging Concepts And Methods. Laredo, Texas, USA: Springer Science+Business Media, 2007.

[11] J. Kontio, L. Lehtola, and J. Bragge, “Using the focus group method in software engineering: obtaining practitioner and user experiences," in International Symposium on Empirical Software Engineering, Redondo Beach, CA, USA, 2004, pp. 271-280.

[12] ISO/IEC TR 15504:1998(E). Information Technology -Software process assessment. Parts 1-9, International Organization for Standardization, 1998.

[13] ISO 9001:2000. Quality management systems - Requirements, International Organization for Standardization, 2000.

[14] SEI, “Capability maturity model for software - cmmi for development 
v1.3," Carnegie Mellon University, Pittsburg, Pennsylvania, USA, Tech. Rep. CMU/SEI-2010-TR-033, Nov. 2010.

[15] K. Schwaber and J. Sutherland. (2017, Nov.) The scrum guide. [Online]. Available: https://goo.gl/ECDWH5

[16] A. Vizcaíno, F. O. García, and M. G. Piattini, Desarrollo Global de Software. Madrid, España: RA-MA, 2014.

[17] E. Hossain, P. L. Bannerman, and D. R. Jeffery, "Scrum practices in global software development: A research framework," in $12^{\text {th }}$ international conference on Product-focused software process improvement, Torre Canne, Italy, 2011, pp. 88-102.

[18] K. L. Then, J. A. Rankin, and E. Ali, “Focus group research: what is it and how can it be used?" Can. J. Cardiovasc. Nurs., vol. 24, no. 1, pp. 16-22, 2014.

[19] A. Qumer and B. Henderson, "An evaluation of the degree of agility in six agile methods and its applicability for method engineering," Information and Software Technology, vol. 50, no. 4, pp. 280-295, Mar. 2008. 